benefit from carrying on work which brought them into daily contact with Europeans. Viewed, therefore, merely in the light of an educational establishment, this department has been of much benefit to the Government by supplying so many intelligent and well-informed officials, al more or less imbued with favourable notions respecting foreigners and a desire to see foreign intercourse extended.

The history of Mr. Ka Pu-wei, who has for several years worked in connection with this department, is almost as remarkable as that of Messrs. Hsü and Hwa. From his childhood he had a strong leaning to mathematical studies; but not being in independent circumstances, he was obliged to support himself by keeping a rice-shop inside the city of Shanghai. Here he prosecuted his studies with such success that he was able to calculate eclipses and to prepare an almanac giving particulars respecting the movements of the heavenly bodies, which he ventured to publish. The Government alone having the authority to publish almanacs, and the country being at the time unsettled by the Taiping rebellion, he was charged with having designs against the Imperial throne, and cast into prison. He narrowly escaped with his life, but suffered imprisonment for above a year, till his friends could procure his release. $\mathrm{He}$ is now chiefly engaged in compiling and publishing a nautical almanac, calculated for the longitude of Shanghai instead of Peking or Greenwich, and in preparing various books of mathematical tables, for all of which his past studies have been an excellent means of preparation.

Equally interesting is the history of $\mathrm{Mr}$. Li Shan-lan, who was for a short time connected with the Translation Department before his removal to Peking, as Professor of Mathematics in the University of that city. He is a native of the Province of Chekiang, and from his earliest years manifested a remarkable genius for the science of numbers. In the year 1845 he began to publish original treatises embracing different problems in the higher mathematics. On one occasion when at Shanghai he went to a chapel where Dr. Medhurst was preaching to a Chinese congregation, and showed him one of these works. This resulted in his being engaged in the London Mission, where Mr. Wylie took him in hand and translated with him several mathematical works of the highest order, as well as Herschel's "Outlines of Astronomy." With Dr. Edkins he translated Whewell's "Mechanics." Nothing in the way of science seemed to come amiss to him. Eventually he commenced Newton's "Principia" with Mr. Wylie, of which he only translated a small portion of the first book. The remainder of the first book he finished at the Kiangnan Arsenal with Mr. Fryer during the few months of his connection with the Translation Department. $\mathrm{He}$ seemed to enter into the most intricate of its problems with the greatest zest and enthusiasm, and often expressed his intense admiration for Newton's genius. His skill in solving the most difficult mathematical questions that could be given him was truly remarkable. Of course there are not many men of his calibre to be found in China; but still no doubt others will be brought to light through the impulse which foreign intercourse is bringing to bear upon the stagnant minds of this long-isolated nation. Now and then a lesser light than $\mathrm{Li}$ Shan-lan appears among the various visitors at the Arsenal, and it is reported that $\mathrm{Ku}$ Shang-chib, a native of Chiu-shan, is in advance of him; but this needs confirmation.

The establishment where the books are printed in the old-fashioned way from wooden blocks was first merely a small room, but has now grown into a separate range of buildings, and employs upwards of thirty hands as block-cutters, printers, bookbinders, \&c., and is superintended by an under-official. Another under-official has charge of the books when printed, and is responsible for the money derived from their sale. About half-a-dozen copyists complete the personnel of the department.

The library of foreign books consists now of several hundred volumes, and forms probably the best collection of the kind in China. It is contemplated to make extensive additions shortly of recent important publications.

It may be mentioned that, as a mark of Imperial favour, various honorary degrees of rank have been conferred upon the native and foreign members of the Translation Department, in acknowledgment of the value of their services. Mr. Fryer, Dr. Kreyer, and Dr. Allen received diplomas entitling them to the third, fourth, and fifth degrees of civil rank respectively.

On various occasions some of the highest officials in the Empire have sent requests for books to be translated, bearing on subjects in which they took particular interest. Notably this has been the case with H. E. Li Hung-chang. Among the high dignitaries who have expressed their satisfaction at the results attained by this department, it may be mentioned that on one occasion, when staying at the Arsenal, H. E. Ting Jih-chang expressed himself in strong language as to the importance which he attached to the translation of books, compared with the work carried on in other departments. The Marquis Tsêng, who resided for a few days at the Arsenal in 1877, and has from the first been in favour of the undertaking, gave Mr. Fryer a Chinese fan, on which he had written by way of compliment a verse of Chinese poetry of his own composition, and which may be freely translated as follows :-

" Nine years have elapsed since our last conversation;

But your translations have been forwarded to me from time to time.

May your fame surpass that of Verbiest and Schaal,

As the electric light exceeds the spark of the glowworm." ( $T o$ be continued.)

\section{THE GREAT VIENNA TELESCOPE}

$T H E$ political and social disturbances in Ireland have of late somewhat diverted attention from the literary and scientific work done in that country. Such work has nevertheless proceeded on its quiet way despite land agitation, failure of crops, or even commercial distress ; and Ireland is to be congratulated on the completion of the fine 27 -inch refracting telescope, designed and con-

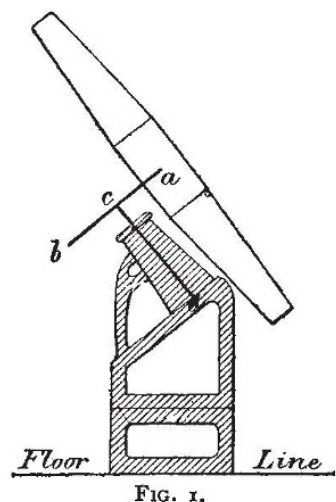

structed by Mr. Howard Grubb of Dublin for the Imperial and Royal Observatory of Vienna.

This telescope is the largest equatorial refractor at present in existence. In the year 1873 Director Littrow, of the National Observatory of Vienna, induced the then Austrian Minister of Public Construction (R. von Stromayer) to consent to the removal of the Observatory from the old site in the Vienna University grounds to a more favourable site, consisting of a level piece of ground 
of some fifteen acres in extent, about 200 feet over the general level of the city, and nearly three miles to the north of the cathedral of St. Stephen's. On this plateal a magnificent edifice has been erected, which measures from north to south 330 feet, and from east to west 240 feet. The general plan of the observatory is that of a

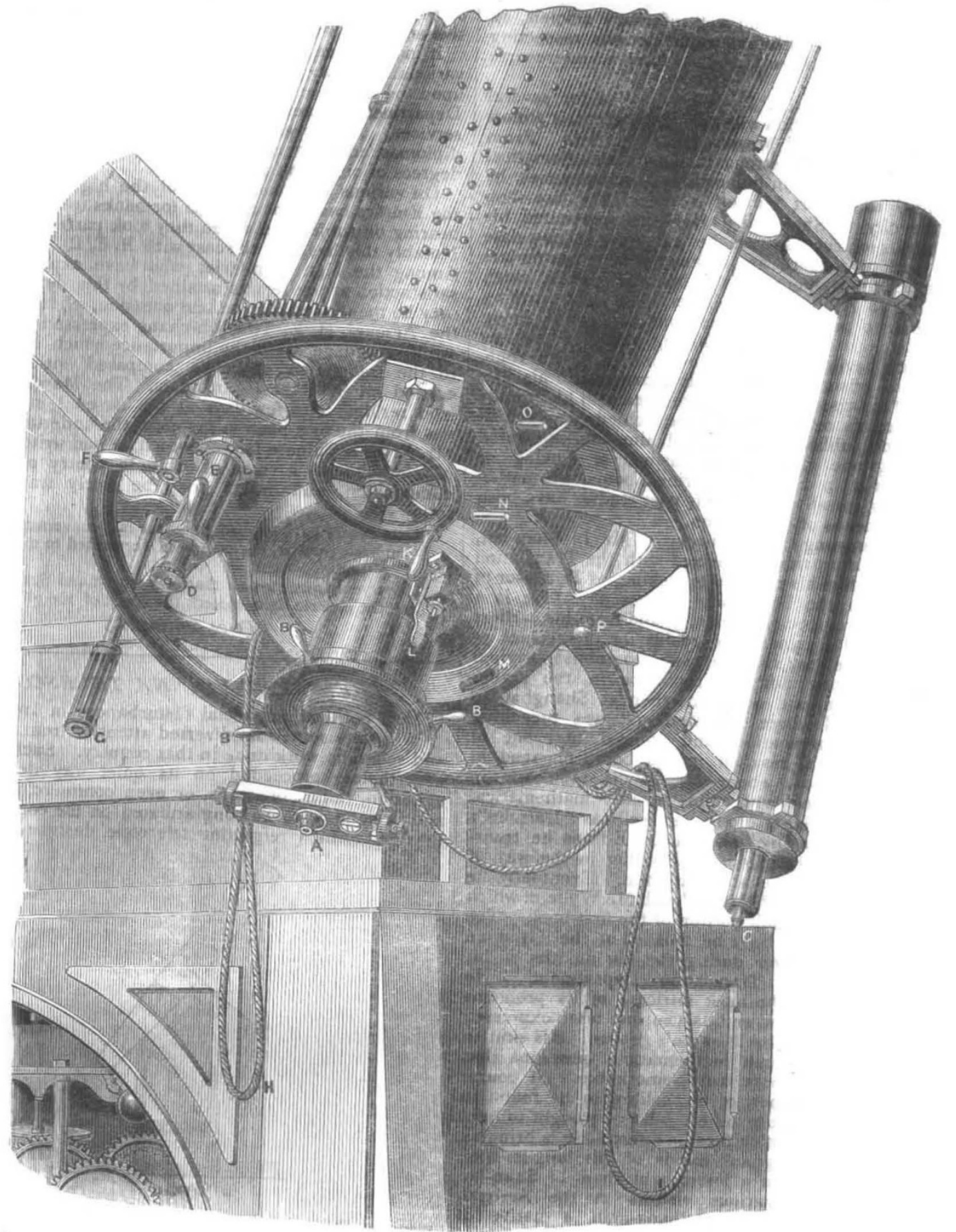

TIG. 2,-Eye-End and Breech-Piece cf Telescofe. A is the micrometer eye-piece; B $B$, handles for working the focussing screw ; c, eye-piece of finder telescope, 4 in. aperture; $D$, eye-p:ece of reader for reading right ascensicn and declinat:on circles; $\mathrm{E}$, handle for revolving same to point to various verniers: $F$, clamping handle in declination; $G$, slow motion hand? $e$ in declination; $\mathrm{H}$, clan ping cords for right ascensicn; $\mathrm{x}$, slow motion cord for right aseension; $\mathrm{k}$, quick mction handle for right ascension and declinaticn mcvements; $\mathrm{L}$, flute key for position circle clamping: through which glass positicn circle is viewed whle illuminated from behind by feam cf light frrm gas-lamp at end of declination axis; windew for slow motion in position ang? ; o, key for throwing into pcsition a set of illuminators for "dark field" illuminaticn of micrcmeter; for throwing into positicn an arm carrying one central mirrcr for "brigbt field" illumination cf micrometer.

Latin cross. One great dome forms the centre, three smaller domes terminate the extremities of three of the short arms, while the fourth arm, looking south, cortains

the library and lecture-rooms, \&c. The south façade is very imposing, and in it are the rooms for the director of the Observatcry. In one of the smaller domes (each 27 
feet in diameter) is placed a 12-inch refractor by Alvan Clark, and it is intended to have in the other two an equatorial for photographic work, and an altazimuth or cometrseeker. It seems a pity that the use of so magnificent a building should in some measure be sacrificed to architectural display, for the splendid south façade being devoted to domestic purposes, an enormous proportion of the observations will of necessity be made over the chimneys of the dwelling-house. The great central tower is 45 feet in diameter, and its dome and the revolving machinery to work it have been supplied by Mr. Howard Grubb, who has also put up all the domes of the smaller towers. The great dome is of a very peculiar construction. It is formed of two thin shells of steel plate varying in thickness; these are riveted on the inside and outside of a very light set of steel plate girders I8 inches deep at base and 9 inches at crown, the whole forming a cellular construction like the top and bottom of the Britannia Tubular Bridge. This form gives enormous stiffness for the amount of material used, besides poșsessing several points of peculiar usefulness for astronomical work, such, the more specially, as keeping the temperature of the dome wonderfully constant, even under most trying circumstances. The total weight of this steel dome, with its ribs and girders, the cast-iron sole plate, and fitting, is about 15 tons, and as the result of a series of very ingenious mechanical contrivances thought out by Mr. Grubb, the tractive force necessary to pull round this huge drum, even when resting, as at Dublin, on a temporary support and insufficiently levelled, was only 70 lbs. All these domes were constructed, so far as the framework went, in Dublin, and they have been placed for some time past in situ at Vienna, under the superintendence of Mr. W. K. Davis, Mr. Grubb's engineer.

The new Observatory having been well advanced in 1874 Director Littrow sent his first assistant (now the General Director), Dr. Ed. Weiss, on a tour of inspection to all the great observatories and astronomical workshops of Europe and America, with the result that Dr. Weiss recommended to his Government that an instrument of at least 26 -inch aperture should be ordered from the establishment of Mr. Howard Grubb, and in the year I 875 the contract between the Austrian Government and Mr. Grubb was signed for a 27 -inch refractor. The mechanical parts were nearly finished in the year 1878 , but the greatest difficulties were experienced by the Messrs. Feil of Paris in obtaining perfect disks of glass for the objective, and it was not until after several trials and towards the close of 1879 that this firm succeeded in sending to Dublin disks that ultimately proved perfect. These had to be worked into the objective at Mr. Grubb's establishment, and on several occasions serious flaws were only discovered at a time when but for them the object-glass would have been complete.

The general form of the equatorial may be described as a modification of the German form. In designing it Mr. Grubb kept in view the fact that while circumpolar motion was very desirable-indeed almost necessaryfor objects from the horizon to, or approaching to, the zenith, it was by no means so essential for objects beyond that to the pole. This will be evident on consideration, for nineteen-twentieths of the objects usually under observation in these latitudes are between the zenith and south horizon, and if one be observed north of the zenith its apparent rate of progression is so slow that a very little motion of the telescope takes place for any given duration of observation. Keeping this in view, Mr. Grubb has adopted the form shown (Fig. I), in which the intersection of the axes $c$ is placed, not over the centre of the pier, but over the north end nearly, and this allows the telescope circumpolar motion for all objects up to the zenith. It should also be observed that this circumpolar motion gives another advantage besides that of nonreversal, viz. that it allows choice of two positions of the telescope in observing almost any object. In observing near the meridian the telescope may be used either to the east or west of the pier, and in observing towards the east or west the telescope can be used either over the polar axis or under. This is sometimes found to be a great convenience. The above considerations were those which influenced Mr. Grubb in deciding on the particular form for the Vienna instrument, and the result is that almost all the advantages of circumpolar motion are obtained without any serious counterbalancing disad. vantages.

To enter into full details of all the various parts of this magnificent telescope would far exceed the space at our command. Up to this it has been thought impossible to apply to large equatorials those many important contrivances to save time and labour which all first-rate

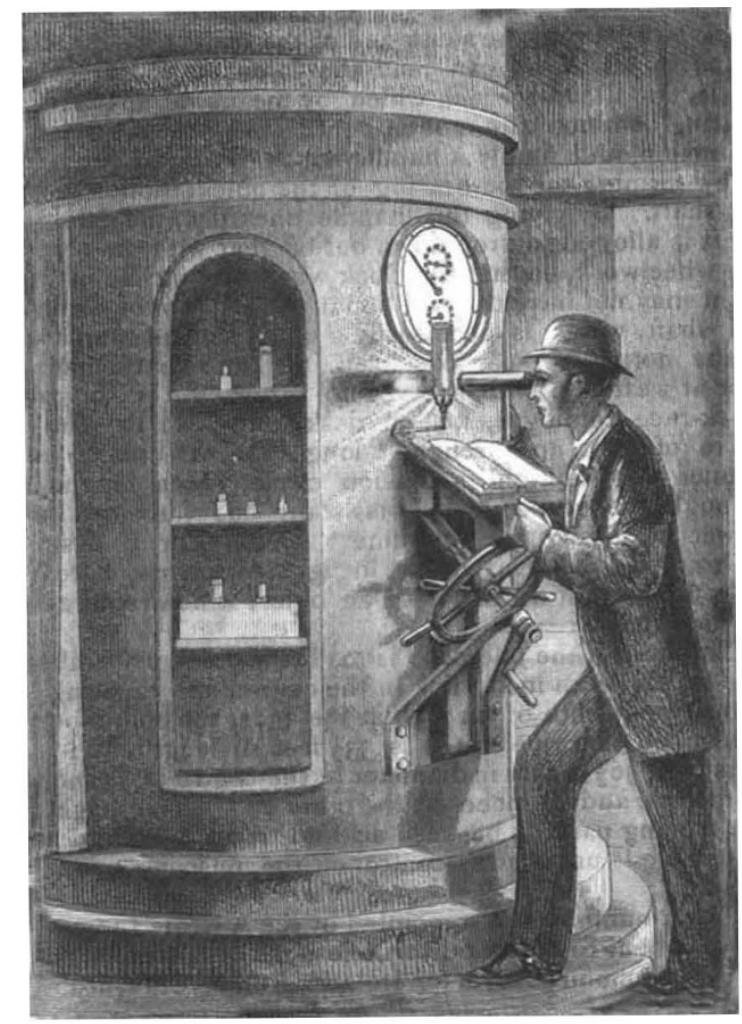

Fig. 3.

instrument-makers would adapt to small instruments, but in this one all such contrivances and many novel adaptations of such have been utilised. To enable our readers to form some idea of the resources within the ready reach of the observer, we, through the kindness of the proprietors of our contemporary, Engineering, give an illustration (Fig. 2) of the eye-end of the tube.

In the largest telescope until now in existence, the great 26-inch refractor at Washington, the oft-recurring operation of reading the circle involved the sending of an assistant with a hand-lamp to climb up some twenty feet of the instrument, and the vernier not being in a fixed place, but moving about with the telescope, the labour and difficulty of this operation are great. In the Vienna instrument Mr. Grubb has so contrived it that the observer sitting in his chair can read the right ascension and declination circles through one single reader, all being illuminated by one gas-lamp hung on the end of the declination axis.

Another wonderful convenience is enabling an assistant 
to easily turn and set the instrument to right ascension. This can be understood from Fig. 3, which is from a photograph. In the case of an instrument of the size of the Vienna equatorial, the observer requires an elaborate stage or platform of variable height and position in order to reach the eye-end, and if he has to move to another object he must descend from his chair or platform and move it before he can move the instrument, and then he has not the facility of sighting objects, but must adopt a sort of tentative process, climbing up and down his stage and moving it and the telescope alternately. To avoid this labour and save time an arrangement is supplied by which the assistant from the ground floor can set the instrument in right ascension, and once set in one direction, the other (declination setting) can be readily managed by the observer. The assistant is supposed to stand at the south end of the pier. He has there before him a desk on which his catalogue and paper can rest, a sidereal clock-face let into the south end of the pier, a reader telescope by which he can read the lower right ascension circle, and a hand-wheel, which by means of shafts and gearing communicate motion to the instrument in right ascension, and finally a handle which is keyed on to a screw forming the toe-bearing of the quick motion driving-shaft. By giving this handle one turn, the driving shaft is allowed to drop down out of gear with the rest of the wheelwork, so that the clock when driving the instrument may not have the additional work to do of driving this shaft, which is necessarily a quick one as compared to the motion of polar axis itself. A lamp is attached to pier at west side, which serves to throw light on sidereal clock-face, catalogue, \&c., on desk, and also to send a beam of light up through a long tube directed to the vernier of the right ascension circle which is visible through the reader. The assistant has therefore full power of setting the instrument roughly, or if desired with any degree of accuracy, in right ascension, or reading off the right ascension of an object which requires to be identified.

The tube of the telescope is made of steel plate about one-eighth of an inch thick in the centre, and tapering to about one-twelfth of an inch at the ends, the points being all lapped and riveted; it is $33 \frac{1}{2}$ feet in length, and lessens from $36 \frac{1}{2}$ inches in diameter in the centre to 27 inches at the one and 12 inches at the other end. The weight of the moving parts is between six and seven tons, and still the whole is under easy control of the muscular power of one arm.

The Commissioners appointed by the Austro-Hungarian Government to report on this telescope consisted of Prof Ball, Astronomer-Royal for Ireland, Earl of Crawfurd and Balcarres, Mr. Huggins, Prof. J. Emerson Reynolds, Earl of Rosse, Prof. Stokes, Dr. G. J. Stoney, and Mr. Walsh, the Austro-Hungarian Consul at Dublin. On March I6 this Commission forwarded to the AustroHungarian Embassy in London their full approval of the performance of the instrument, thus marking the successful completion of the largest refracting telescope in existence.

It will be remembered that Mr. Grubb has built among other fine instruments the great Melbourne Reflector, the largest equatorially-mounted telescope known. He has not rested on his laurels, but is now to be cordially congratulated on a still greater accomplishment.

\section{WHEWELL ON COLOURING GEOLOGICAL $M A P S$}

$\mathrm{NE}$ of the subjects to be brought forward for discussion at the International Geological Congress to be held this year at Bologna is the unification des figurés; that is to say, an attempt will be made to come to some agreement as to the signs and colours to be used on geological maps. Two things have to be indicated: succession, i.e. the stratigraphical position of the rock; and formation, by which, adopting a terminology now in much favour on the Continent, we mean the lithological character and origin of the rock, and not, as is generally understood by the word in this country, a subdivision of the stratigraphical series. I have found among Prof. Sedgwick's papers a scheme drawn up by Dr. Whewell nearly half a century ago, which I have thought might be of use to those who are considering this question, and of interest to many besides. It is dated from Dublin, 1835 , where he was attending the meeting of the British Association, and it was probably suggested by the publication of Griffiths' map.

William Smith shaded up to the lowest beds of the various groups into which he divided the strata, in order by contrast to mark more strongly the coming in of a new series, but he does not seem to have adopted any system beyond sometimes taking such tints as were suggested by the predominant colours of the rocks represented. Salter, I remember, proposed a scale of colours founded on the spectrum, but the scheme proposed by the late Master of Trinity I do not remember to have seen put forward before.

Trin. Coll., Cambridge, April 26 THOS. MCK. HUGHES

\section{Proposal for a Systematic Scale of Geological Colours}

THE objects which it would be desirable to secure in fixing the scale of colours for a geological map appear to be the following:-

I. That the different members of the geological series should be coloured in a manner somehow depending on their place in that series, so that successive rocks are distinguished.

2. That this distinction (of succession) should be governed by some general principle, and should not be merely arbitrary; so that without referring to the index list the colour itself should show the difference of older and younger in the rock.

3. That the colours should also show the great leading differences of the material of the strata (limestone, sandstone, clay), so that without referring to the scale these differences should be known from the colour.

4. 'That igneous rocks should by some general circumstance in the colour be distinguished from sedimentary.

5. That the colours which are brought near each other by proximity of succession should be strongly contrasted.

The following method would, I think, secure these objects. It proceeds on the supposition that there are three primary colours-Red, Yellow, Blue - and that any two of these mixed in considerably different proportions make several shades of intermediate colour; thus between red and yellow we have many shades of orange, proceeding from pure red, through reddish orange, to orange, yellowish orange, and pure yellow; in like manner we have many shades of green between yellow and blue, and many shades of purple between red and blue. Our scale can be subdivided as far as these shades are distinguishable. We have also black, which can be combined in various proportions with each of the simple colours; thus black with successive doses of red makes brown more and more red.

The general principles which I propose are these :-

I. Let one of the above four simple colours represent the material and another the order of succession, and let surcessive mixtures represent successive strata of the same material. Thus let the oldest limestone be pure blue, let doses of yellow be added to mark newer and newer limestones, the chalk being a very yellow green; thus all the oolite series will be green of different shades.

2 . Let the simple colour which represents succession be different for different materials, thus let blue represent succession for the clays, and let all the clays be purple, the oldest therefore being the reddest, and the newest the bluest purple. 